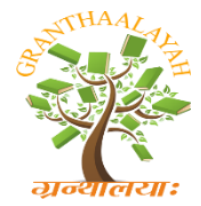

\author{
INTERNATIONAL JOURNAL OF RESEARCH - \\ GRANTHAALAYAH \\ A knowledge Repository
}

Science

\title{
BACK PROPAGATION NEURAL NETWORK TECHNIQUE FOR REDUCTION OF REAL POWER LOSS
}

\author{
Dr K. Lenin *1 \\ ${ }^{* 1}$ Professor, Department of EEE, Prasad V.Potluri Siddhartha Institute of Technology, Kanuru,
}

Vijayawada, Andhra Pradesh -520007, India

\begin{abstract}
In this work particle swarm optimization algorithm has been hybridized with Back propagation neural network (PSBP) to solve the reactive power problem. Proposed PSBP methodology improves search. PSO algorithm to optimize the original weight, threshold value and when the algorithm ends, optimal point can be found- on the base of PSO algorithm; Back propagation neural network algorithm to search overall situation and then achieve the network training goal. In the particle swarm, every particle's position represents weights set among the network during the resent iteration. In order to evaluate the proposed algorithm, it has been tested on IEEE 118 bus system and compared to other algorithms and simulation results show that proposed algorithm reduces the real power loss effectively.
\end{abstract}

Keywords: Optimal Reactive Power; Transmission Loss; Particle Swarm; Network.

Cite This Article: Dr K. Lenin. (2018). "BACK PROPAGATION NEURAL NETWORK TECHNIQUE FOR REDUCTION OF REAL POWER LOSS.” International Journal of Research - Granthaalayah, 6(12), 140-146. 10.29121/granthaalayah.v6.i12.2018.1100.

\section{Introduction}

To minimize the true power loss is key aim in this reactive power optimization problem. Various techniques [1-8] have been applied to solve optimal reactive power problem. Yet many difficulties are found while solving problem due to various types of constraints. After that many Evolutionary techniques [9-20] applied to solve the reactive power problem, but many algorithms stuck in local optimal solution also failed to balance the Exploration \& Exploitation during the search of global solution. In this work particle swarm optimization algorithm has been hybridized with Back propagation neural network (PSBP) to solve the reactive power problem. Proposed PSBP methodology improves search [21-36]. Improved PSO algorithm to optimize the original weight, threshold value and when the algorithm ends, optimal point can be found- on the base of PSO algorithm; Back propagation neural network algorithm to search overall situation and then achieve the network training goal. In the particle swarm, every particle's position represents weights set among the network during the resent iteration. In order to evaluate the proposed algorithm, it has 
been tested on IEEE 118 bus system and compared to other algorithms and simulation results show that proposed algorithm reduces the real power loss effectively.

\section{Objective Function}

\section{A. Real Power Loss}

Objective of the problem is to reduce the true power loss:

$\mathbf{F}=\mathbf{P}_{\mathrm{L}}=\sum_{\mathrm{k} \in \mathrm{Nbr}} \mathbf{g}_{\mathrm{k}}\left(\mathrm{V}_{\mathrm{i}}^{2}+\mathrm{V}_{\mathrm{j}}^{2}-2 \mathrm{~V}_{\mathrm{i}} \mathrm{V}_{\mathrm{j}} \cos \theta_{\mathrm{ij}}\right)$

\section{B. Amplification of Voltage Profile}

Voltage deviation given as follows:

$F=P_{L}+\omega_{v} \times$ Voltage Deviation

Voltage deviation given by:

$$
\text { Voltage Deviation } \quad=\sum_{\mathrm{i}=1}^{\mathrm{Npq}}\left|\mathrm{V}_{\mathrm{i}}-\mathbf{1}\right|
$$

C. Constraint (Equality)

$$
\mathbf{P}_{\mathbf{G}}=\mathbf{P}_{\mathbf{D}}+\mathbf{P}_{\mathbf{L}}
$$

\section{Constraints (Inequality)}

In equality constraints are given by,

$$
\begin{aligned}
& \mathbf{P}_{\text {gslack }}^{\text {min }} \leq \mathbf{P}_{\text {gslack }} \leq \mathbf{P}_{\text {gslack }}^{\text {max }} \\
& \mathbf{Q}_{\mathrm{gi}}^{\min } \leq \mathbf{Q}_{\mathrm{gi}} \leq \mathbf{Q}_{\mathrm{gi}}^{\max }, \mathbf{i} \in \mathbf{N}_{\mathrm{g}} \\
& \mathbf{V}_{\mathbf{i}}^{\min } \leq \mathbf{V}_{\mathbf{i}} \leq \mathbf{V}_{\mathbf{i}}^{\max }, \mathbf{i} \in \mathbf{N} \\
& T_{i}^{\min } \leq T_{i} \leq T_{i}^{\max }, i \in N_{T} \\
& \mathbf{Q}_{c}^{\min } \leq \mathbf{Q}_{c} \leq \mathbf{Q}_{\mathrm{C}}^{\max }, \mathbf{i} \in \mathbf{N}_{\mathrm{C}}
\end{aligned}
$$

\section{Hybridized Algorithm}

The optimal algorithm of improved particle swarm is not dependent of fields of problems. However, it uses the code of decision variable as operation object and adaption function as searching objects. Furthermore, it can use the information from various searching points. It applies to solve the problem about nonlinearity and non-differentiable function and multiple objectives.

The "I" particle represent a D-dimensional vector, 
$X_{i}=\left(X_{i 1}, X_{i 2}, \ldots X_{i d}\right)$ It means that the "i" particle represents its position in this space. Every position of particle " $X$ " is a potential solution. If we put " $x$ " into objective function, we can know the adaptive value. We can know whether the " $x$ " is the optimal answer based on the adaptive value. The speed of particle is also a $\mathrm{D}$-dimensional, it also recorded as $v_{i}=\left(v_{i 1}, v_{i 2}, \ldots v_{i d}\right)$.We record the particle $\mathrm{I}$ to the $\mathrm{h}$ times, the optimal position was $P_{i}=\left(P_{i 1}, P_{i 2}, \ldots P_{i d}\right)$. All the particles to the $\mathrm{h}$ times, the optimal position was $P_{g d}=\left(P_{i 1}, P_{i 2}, \ldots P_{i d}\right)$. The basic formulas are as follows:

$v_{i d}^{t+1}=w v_{i d}^{t}+c_{1} r_{1}^{t}\left(P_{i d}^{t}-x_{i d}^{t}\right)+c_{2} r_{2}^{t}\left(P_{g d}^{t}-x_{i d}^{t}\right)$

$x_{i d}^{t+1}=x_{i d}^{t}+v_{i d}^{t+1}$

Where, $\boldsymbol{c}_{\mathbf{1}} \& \boldsymbol{c}_{\mathbf{2}}$ : Speeding coefficient, adjusting the maxim step length that flying the best particle in whole situation and the individual best particle respectively. Appropriate $c_{1}$ and $c_{2}$ speed up the convergence and avoid falling into partial optimality $\mathbf{r}_{1} \& r_{2}$ : Random number between 0 and 1 , for controlling the weight of speed W: Inertia factor. It was oriented toward overall searching. We usually take the original value as 0.9 and make it to 0.1 with the addition and reduction of the times of iteration. It mainly used to total searching, making the searching space converge to a certain space. LDW (Linearly Decreasing Inertia Weight) is given by,

$w=w_{\max }-\frac{t \times\left(w_{\max }-w_{\min }\right)}{t_{\max }}$

Where, $w_{\max } \& w_{\min }$ : The maximum and minimum value of $\mathrm{W}$, t: The step of iteration, $t_{\max }$ : The maximum iteration step.

In PSO method of nonlinear variation weight with momentum to improve this method and given by

$w=w_{\max }-\frac{t \times\left(w_{\max }-w_{\min }\right)}{2^{\theta} t_{\max }}$

$2^{\theta}$ is momentum, when in $\theta=t / t_{\text {max }}, t$ is smaller, $2^{\theta}$ is near to 1 and $w$ is near to $w_{\text {max }}$., it ensure the ability of total searching. With the increasing of $t, w$ reduces in non linearity, ensuring the searching ability in partial areas. In the later period $\left(t=t_{\max }\right)$, avoiding the problems caused by the decrease of $w$. That is, the reduction ability of total searching and the decline of variety.

The node action function of Back propagation neural network is generally " $\mathrm{S}$ " function. Common activation function $\mathrm{f}(\mathrm{x})$ is derivable sigmoid function:

$f(x)=\frac{1}{1+e^{-x}}$

Error function $\mathrm{R}$ is:

$R=\frac{\sum\left(Y_{m j}-Y_{j}\right)^{2}}{2}(j=1,2, \ldots, n)$ 
In this formula, $Y_{j}$ is expected out $Y_{m j}$ is actual output $\mathrm{n}$ is sample length.

The uniform expression of weight modified formula is:

$w_{i j}^{(t+1)}=w_{i j}(t)+\eta \delta_{p j} o_{p j}$

Step 1: Select n samples as a training set.

Step 2: Initialize weight and biases value in neural network. The initialized values are always random numbers between $(-1,1)$. Every sample in the training set needs the following processing: Step 3: According to the size of every connection weight, the data of input layer are weighted and input into the activation function of hidden layer and then new values are obtained. According to the size of every connection weight, the new values are weighted and input into the activation function of output layer and the output results of output layer are calculated.

Step 4: If there exists error between output result and desired result, the calculation training is wrong.

Step 5: Adjust weight and biases value.

Step 6: According to new weight and biases values, the output layer is calculated. The calculation doesn't stop until the training set meets the stopping condition.

The tangible hybridization process can be narrated as follows:

Step 1: Initialization: $n_{i}$ is the number of neurons in the hidden layer no representing the number of neurons in input layer. So, the dimension of particle swarm D is:

$D=n_{i} \times n_{h}+n_{h} \times n_{\circ}+n_{h}++n_{\circ}$

Step 2: Setting fitness function of particle swarm' in this text, we choose mean square error in BP Neural Network as fitness function of particle swarm:

$E=\frac{1}{M} \sum_{K}^{m} \sum_{j-1}^{n_{o}}\left(y_{k j}-\overline{y_{k J}}\right)$

$y_{k j}$ : The output in theory based on sample $\mathrm{K}$

$\overline{y_{k J}}$ : The virtual output based on sample $\mathrm{K}$

M: The number of Neural Network

Step 3: Using the improved particle swarm algorithm to optimize the weight and the threshold value of BP network.

Step 4: Coming to the optimal weight and the threshold value; as follows:

$g_{\text {best }}=\left[\begin{array}{c}h_{1}, h_{2}, \ldots, h_{n_{h}}, o_{1}, o_{2}, \ldots, o_{n_{o}}, i h_{1}, i h_{2}, \ldots, i h_{n_{i} \times n_{h^{\prime}}} \\ h o_{1}, h o_{2}, \ldots, h_{o_{h} \times n_{o}}\end{array}\right]$

$h_{i}\left(=1,2, \ldots, n_{k}\right):$ the threshold value in the hidden layer, $o_{i}\left(i=1,2, \ldots, n_{o}\right)$ :

The threshold value in the output layer, $i h_{i}\left(i 1,2, \ldots, n_{i} \times\right)$ : the weight between

the hidden layer and

the input layer, $h_{i}\left(i=1,2, \ldots, n_{h} \times n_{o}\right)$ :

the weight between the hidden layer and 
the output layer

Step 5: Letting the optimal weight and the threshold value as the original weight and the threshold value of BP network and then put them into Neural Network for training. Adjusting the weight and the threshold value based on BP algorithm until the function index of the network's Mean Square Error (MSE) <e. e is the preset expected index.

\section{Simulation Results}

In IEEE 118 bus system [37] is used as test system to validate the performance of the proposed algorithm. Table 1 shows limit values.

Table 1: Limitation OF REACTIVE power sources

\begin{tabular}{|l|l|l|l|l|l|l|l|}
\hline Bus number & 5 & 34 & 37 & 44 & 45 & 46 & 48 \\
\hline Maximum value of QC & 0.000 & 14.000 & 0.000 & 10.000 & 10.000 & 10.000 & 15.000 \\
\hline Minimum value of QC & -40.000 & 0.000 & -25.000 & 0.000 & 0.000 & 0.000 & 0.000 \\
\hline Bus number & 74 & 79 & 82 & 83 & 105 & 107 & 110 \\
\hline Maximum value of QC & 12.000 & 20.000 & 20.000 & 10.000 & 20.000 & 6.000 & 6.000 \\
\hline Minimum value of QC & 0.000 & 0.000 & 0.000 & 0.000 & 0.000 & 0.000 & 0.000 \\
\hline
\end{tabular}

Table 2 show the comparison of results.

Table 2: evaluation of results

\begin{tabular}{|l|l|l|l|l|}
\hline $\begin{array}{l}\text { Active power loss - } \\
\text { Minimum \& Maximum } \\
\text { values }\end{array}$ & $\begin{array}{l}\text { Methodology - } \\
\text { BBO } \\
{[\mathbf{3 8}]}\end{array}$ & $\begin{array}{l}\text { Methodology } \\
\text { ILSBBO/ } \\
\text { strategy1 } \\
{[\mathbf{3 8}]}\end{array}$ & $\begin{array}{l}\text { Methodology } \\
\text { ILSBBO/ } \\
\text { strategy1 } \\
{[\mathbf{3 8}]}\end{array}$ & PSBP \\
\hline Minimum value & 128.770 & 126.980 & 124.780 & 122.784 \\
\hline Maximum value & 132.640 & 137.340 & 132.390 & 126.296 \\
\hline Average value & 130.210 & 130.370 & 129.220 & 124.108 \\
\hline
\end{tabular}

\section{Conclusion}

In this paper a Proposed PSBP methodology successfully solved the reactive power problem. PSO algorithm to optimize the original weight, threshold value and when the algorithm ends, optimal point can be found- on the base of PSO algorithm; Back propagation neural network algorithm to search overall situation and then achieve the network training goal. In order to evaluate the proposed algorithm, it has been tested on IEEE 118 bus system and compared to other algorithms and simulation results show that proposed algorithm reduces the real power loss effectively.

\section{References}

[1] H.W. Dommel, and W.F. Tinney, "Optimal power flow solutions," IEEE Trans. Power App. Syst, vol. PAS-87, pp. 1866-1876, 1968.

[2] L. D. B. Terra and M. J. Short: "Security constrained reactive power dispatch," IEEE Trans. on power systems, Vol. 6, No. 1, February 1991. 
[3] K. H. A. Rahman and S. M. Shahidehpour: "Application of fuzzy set theory to optimal reactive power planning with security constraints," IEEE Trans. on power systems, Vol. 9, No.2, May 1994, pp. 589-597.

[4] F.C. Lu, Y.Y. Hsu:"Reactive power/voltage control in a distribution substation using dynamic programming", IEE Proc. Gener., Transm. And Distrib. vol. 142, no. 6, pp. 639-645, 1995.

[5] A.Monticelli , M .V.F Pereira , and S. Granville , "Security constrained optimal power flow with post contingency corrective rescheduling", IEEE Transactions on Power Systems :PWRS-2, No. 1, pp.175-182.,1987.

[6] Deeb N, Shahidehpur S.M, Linear reactive power optimization in a large power network using the decomposition approach. IEEE Transactions on power system 1990: 5(2): 428-435

[7] E. Hobson,'Network consrained reactive power control using linear programming, 'IEEE Transactions on power systems PAS -99 (4), pp 868=877, 1980.

[8] Abdul Rahman K.H., Shahidehpour S.M. and Daneshdoost M., "AI approach to optimal VAR control with Fuzzy reactive loads", IEEE Transactions on Power Systems, 10 (1995) 88-97

[9] Q. H. Wu, Y. J. Cao, and J. Y. Wen, "Optimal reactive power dispatch using an adaptive genetic algorithm,” Int. J. Elect. Power Energy Syst., vol. 20, Aug. 1998, pp. 563-569.

[10] Victor H Q, Geraldo L T, "Interior point method and their application to power systems: a classification of publication and software codes," IEEE Transactions on Power Systems, 2000, 15(1): 170-175.

[11] S. Naka,T.Genji, Y. Fukuyama, "A hybrid particle swarm optimization for distribution state estimation", IEEE Transations on Power System, 18(1), pp60-68, 2003.

[12] Zhanhong, Wei Zhihua Cui, Jianchao Zeng, "Social Cognitive Optimization Algorithm with Reactive Power Optimization of Power System," International Conference on Computational Aspects of Social Networks pp. 11-14, 2010

[13] PU Yonghong, LI Yi, "An improved genetic algorithm for reactive power optimization," Proceedings of the 30th Chinese Control Conference, Yantai, China, July 22-24, 2011, pp 21052109.

[14] Himmat Singh, Laxmi Srivastava, "Multi-object reactive power management using differential evolution," International conference Power electronics (IICPE) 2012 pp.1-6

[15] Bhagat Singh Prajapati, Laxmi Srivastava, "Multi-Objective Reactive Power Optimization Using Artificial Bee Colony Algorithm," International Journal of Engineering and Innovative Technology (IJEIT) pp. 126-131 volume 2, Issue 1, July 2012.

[16] Maknouninejad, A.; Qu, Z.H. Realizing unified microgrid voltage profile and loss minimization: A cooperative distributed optimization and control approach. IEEE Trans. Smart Grid 2014, 5, $1621-1630$.

[17] Win, T.S.; Hisada, Y.; Tanaka, T.; Hiraki, E.; Okamoto, M.; Lee, S.R. Novel simple reactive power control strategy with DC capacitor voltage control for active load balancer in three-phase four-wire distribution systems. IIEEE Trans. Ind. Appl. 2015, 51, 4091-4099.

[18] Zhang, W.; Liu, W.; Wang, X.; Liu, L.; Ferrese, F. Online optimal generation control based on constrained distributed gradient algorithm. IEEE Trans. Power Syst. 2015, 30, 35-45.

[19] Chen, S.H.; Hu, W.H.; Su, C.; Zhang, X.; Chen, Z. Optimal reactive power and voltage control in distribution networks with distributed generators by fuzzy adaptive hybrid particle swarm optimization method. IET Gener. Transm. Distrib. 2015, 9, 1096-1103.

[20] Zheng, W.; Wu, W.; Zhang, B.; Sun, H.; Liu, Y. A fully distributed reactive power optimization and control method for active distribution networks. IEEE Trans. Smart Grid 2016, 7, 1021-1033.

[21] Eberhart, R.C. and J. Kennedy, 1995. A new optimizer using particle swarm theory. Proceeding of the 6th International Symposium on Micro Machine and Human Science, pp: 39-43.

[22] Eberhart, R.C. and Y. Shi, 2001. Particle swarm optimization: Development, applications and resources. Proceeding of Congress on Evolutionary Computation, Piscataway, NJ IEEE Press, pp: 81-86. 
[23] Hai-Dong, Z., M. XU-Dong and L. Shi-Pin, 2003. Military plane fault prediction system based on neural network model [J]. Syst. Eng. Electron., 25(7): 894-896.

[24] Hao, P. and H. Xiao-Lei, 2008. BP network training algorithm based on particle swarm optimization. Comp. Eng. Appl., 44(9): 67-69.

[25] Jiang-Hong, H., L. Zheng-Rong and W. Zhen-Chun, 2006. Adaptive particle optimization algorithm and simulation. J. Syst. Simul., 18(10): 2969-2971.

[26] Jie-Ping, C., C. Dao-Cai and L. Li, 2009. Application of BP network model based on PSO for the forecast of drought and flood. J. Shengyang Agric. Univ., 40(1): 118-121.

[27] Jin-Yong, M., H. Chang-Qing, G. Hua and L. Kejie, 2004. Study on fault forecasting of air control equipment based on neural network. Syst. Eng. Electron., 26(7): 992-993.

[28] Kennedy, J. and R.C. Eberhart, 1995. Particle swarm optimization. Proceeding of IEEE International Conference on Neural Networks, Perth, Australia, pp: 1942-1948.

[29] Michael, J.C., E.M. David, J.S. Thomas and A. Malhotra, 1993. Comparison of electronicsreliability assessment approaches. IEEE Trans. Reliabil., 42(4): 542-546.

[30] Shan-Yu, Y. and W. Hong-De, 2005. Analysis on main fan first failure time based on neural network technique. J. China Coal Soc., 30(6): 741-745.

[31] Xiang, L., C. Ji-Feng and X. Jun, 2008. Power demand forecasting based on BP neural network optimized by clonal selection particle swarm. J. Hunan Univ., 35(6): 41-52.

[32] Xiao-Rong, W. and L. Shu-Xian, 2008. Study on BP neural network optimization based on improved PSO algorithm. J. Bohai Univ., 29(2): 189-192.

[33] Xiu-Ye, W. and P. Hong-Xia, 2010. The Improvement of Particle Swarm and Intelligent Trouble Diagnosis. China Defense Press, Beijing, pp: 101-102.

[34] Xuan, H., Z. Jun and Z. Zhi-Hui, 2009. Faster particle swarm optimization with random inertia weight. Comp. Eng. Design, 30(3): 647-650.

[35] Yi-Shan, X., Z. Bi and Y. Xiu-Wen, 2009. BP neural network and its applications based on improved PSO. Comp. Eng. Appl., 45(35): 233-235.

[36] Ying-Jie, L. and H. Chang-Hua, 2005. The performance analysis of missile inertia device fault prediction based on neural networks. Tact. Miss. Technol., 27(2): 52-55.

[37] IEEE, "IEEE 118, 300 -test systems", (1993), http://www.ee.washington.edu/trsearch/pstca/.

[38] Jiangtao Cao, Fuli Wang and Ping Li, "An Improved Biogeography-based Optimization Algorithm for Optimal Reactive Power Flow", International Journal of Control and Automation Vol.7, No.3 (2014), pp.161-176.

\footnotetext{
*Corresponding author.

E-mail address: gklenin@ gmail.com
} 